\title{
Revistas científicas eletrônicas: discussão em sete momentos
}

\section{Joana Coeli Ribeiro Garcia}

Doutora em ciência da informação, Universidade Federal do Rio de Janeiro (UFRJ), Rio de Janeiro-RJ, Brasil. Professora associada da Universidade Federal da Paraíba (UFPb), Paraíba - PB, Brasil.

FERREIRA, S. M. P.; TARGINO, M. das G. (Org). Acessibilidade e visibilidade de revistas científicas eletrônicas. São Paulo: Senac São Paulo, Cengage Learning, 2010.354p.

ISBN - 978-85-396-0035-9 (Editora Senac São Paulo). ISBN - 978-85-221-0990-6(Cengage Learning)

Nos últimos anos, vem se acentuando a discussão sobre revistas científicas, tomando como base a implantação do sistema Qualis de qualidade de publicações (livros e revistas), sob a responsabilidade da Coordenação de Aperfeiçoamento de Pessoal de Nível Superior (Capes). No caso específico das revistas científicas, editores, autores e referees se deparam com questões novas que retomam ao passado, mas que necessitam ser enfrentadas para que seus títulos alcancem a qualidade necessária e exigida por essa agência de fomento. De outra parte, a Associação Brasileira de Editores Científicos (Abec) promove eventos que propiciam aos que se encontram à frente das revistas brasileiras encontrar um denominador comum ou um caminho que satisfaça a todos.

As pesquisadoras em ciência da informação com atuação sistemática junto à Sociedade Brasileira de Estudos Interdisciplinares da Comunicação Social (Itercom) Sueli Mara Soares Pinto Ferreira e Maria das Graças Targino, atentas às questões que se originam numa ou noutra área, num ou noutro fórum, tomaram a si a incumbência de reunir textos de autores nacionais e estrangeiros em três títulos subsequentes. De início, o título Preparação de revistas científicas: teoria e prática (2005), editado por Reichmann \& Autores Editores. Mais adiante, desta vez sob o encargo da Editora Senac São Paulo em coedição com a Cengage Learning, Mais sobre revistas cientificas: em foco a gestão (2008). A terceira obra ora apresentada, Acessibilidade e visibilidade de revistas eletrônicas, final de 2010, está publicada também pelas duas últimas editoras, as quais, reconhecidamente, primam em manter a excelência acadêmica por meio de conteúdos especializados e priorizam a distribuição nacional, um dos sérios problemas das edições de teor acadêmico e / ou científico.

A partir do próprio título, deduz-se que se trata de uma publicação que abrange facetas diferenciadas das revistas, em especial, dos títulos de caráter científico e em suporte eletrônico. Incorpora sete grandes momentos: Acesso aberto e divisão entre ciência predominante e ciência periférica; Motivação para publicar em revistas científicas: estudo nas áreas de ciências da comunicação e ciência da informação; Percepção sobre acesso e visibilidade dos repositórios digitais e das revistas eletrônicas; Limites e potencialidades da avaliação científica: crítica epistemológica à cobertura de bases de dados e à construção de indicadores; Como usar - e se beneficiar - do formato RSS (Really Simple Syndication) para disseminação de informação em revistas científicas eletrônicas; Métricas alternativas de avaliação do impacto e do uso de revistas eletrônicas: estudo em ciências da comunicação.

São sete capítulos sob encargo de 11 autores. Dentre eles, três mexicanos e um canadense. A distinção da proveniência geográfica dos autores ao publicar no 
Brasil demonstra que em tempos de globalização busca-se a qualidade das revistas científicas impressas ou eletrônicas, desconsiderando ou ao menos minimizando a existência de países predominantes ou países periféricos, de grupos poderosos e concorrentes ou instituições, associações e revistas relevantes. A pretensão é demonstrar a rede existente em prol de temáticas que envolvem as revistas científicas, na atualidade, como instrumento essencial ao desenvolvimento científico e tecnológico de quaisquer nações.

Ao longo de sua trajetória para difundir o tema - revistas científicas - as duas autoras divulgam textos que perpassam temas tradicionais ( a exemplo da questão da autoria e coautoria e / ou redação técnica) até proposições de métricas alternativas para avaliação do impacto das revistas. Neste caso, nos referimos ao último capítulo de Acessibilidade e visibilidade de revistas científicas eletrônicas, em que Sueli Mara e Maria das Graças Targino demonstram intenção de associar suas ideias ao editorial de Clinics, janeiro de 2011, intitulado Reflexões críticas sobre os três erres, ou os periódicos brasileiros excluídos. Nele, o autor, Maurício Rocha e Silva, sugere que autores, editores e avaliadores solicitem à Capes considerar, quando da avaliação do triênio 2010-2012, a ser divulgado em 2013, o fator de impacto do SCImago quanto no SciELO o número de periódicos tende a aumentar no ranking dos que apresentam fator de impacto acima de zero. Isso nos colocaria em situação confortável porquanto o número de periódicos a ser considerado pela Capes seria bem maior que o atual.
Decerto, o capítulo do livro 3, Métricas alternativas de avaliação do impacto e uso de revistas eletrônicas: estudo em ciências da comunicação, mantém maior abrangência do que o editorial citado, e considera como fator de impacto o número de visitas e o download de revistas, sobretudo em ciências da comunicação. De qualquer forma, é evidente que a busca por métricas alternativas ocupa espaço entre os cientistas. Isto revela, talvez, certa insatisfação com a adoção restrita de tão-somente aquelas que estão indicadas pelo Institute for Scientific information (ISI) / Thompson, introduzidas no índice de citação científica do Science Citation Index (SCI), utilizado pela Capes para qualificar as revistas nas quais os docentes dos diversos programas brasileiros de pós-graduação publicam. Há a sugestão de inclusão de outros índices na próxima avaliação, inclusive um formulado no Brasil. Esta representa, também, possibilidade de desdizer a prevalência de uma ciência predominante em oposição a uma ciência periférica ou, no mínimo, efetivar o primeiro passo neste sentido.

É, pois, a estratégia que adotamos para divulgar a discussão, em sete momentos, acerca das revistas científicas eletrônicas, liderada pelas organizadoras da coletânea e, ao mesmo tempo, expandir o conteúdo dos três erres do editorial do Clinics.

Fonte: ROCHA E SILVA, Mauricio. Editorial: reflexões críticas sobre os três erres, ou os periódicos brasileiros excluídos. Clinics, v.66,n. 1, p. 3-7, 2011.

Recensão submetida em 12/03/2012 e aceita em 12/03/2012. 